\title{
Laser Enhanced Hydrogen Passivation of Silicon Wafers
}

\author{
Lihui Song, ${ }^{1}$ Alison Wenham, ${ }^{1}$ Sisi Wang, ${ }^{1}$ Phillip Hamer, ${ }^{1}$ \\ Mohammad Shakil Ahmmed, ${ }^{2}$ Brett Hallam, ${ }^{1}$ Ly Mai, ${ }^{1}$ Malcolm Abbott, ${ }^{1}$ \\ Evatt R. Hawkes, ${ }^{1}$ CheeMun Chong, ${ }^{1}$ and Stuart Wenham ${ }^{1}$ \\ ${ }^{1}$ School of Photovoltaic and Renewable Energy Engineering, UNSW, Sydney, NSW 2052, Australia \\ ${ }^{2}$ School of Mechanical and Manufacturing Engineering, UNSW, Sydney, NSW 2052, Australia \\ Correspondence should be addressed to Lihui Song; lihui.song@unsw.edu.au
}

Received 19 December 2014; Revised 6 March 2015; Accepted 13 March 2015

Academic Editor: Xuegong Yu

Copyright (C) 2015 Lihui Song et al. This is an open access article distributed under the Creative Commons Attribution License, which permits unrestricted use, distribution, and reproduction in any medium, provided the original work is properly cited.

\begin{abstract}
The application of lasers to enable advanced hydrogenation processes with charge state control is explored. Localised hydrogenation is realised through the use of lasers to achieve localised illumination and heating of the silicon material and hence spatially control the hydrogenation process. Improvements in minority carrier lifetime are confirmed in the laser hydrogenated regions using photoluminescence (PL) imaging. However with inappropriate laser settings a localised reduction in minority carrier lifetime can result. It is observed that high illumination intensities and rapid cooling are beneficial for achieving improvements in minority carrier lifetimes through laser hydrogenation. The laser hydrogenation process is then applied to finished screen-printed solar cells fabricated on seeded-cast quasi monocrystalline silicon wafers. The passivation of dislocation clusters is observed with clear improvements in quantum efficiency, open circuit voltage, and short circuit current density, leading to an improvement in efficiency of $0.6 \%$ absolute.
\end{abstract}

\section{Introduction}

Hydrogen passivation has received intense interest due to its ability to increase the effective electronic quality of silicon material, therefore creating the possibility to fabricate high efficiency silicon solar cells on low quality silicon wafers that can be fabricated at a lower cost than conventional wafers [1, 2]. Hydrogen is reported to passivate crystallographic defects in multicrystalline silicon, metal impurities, and the surfaces of crystalline silicon [3-9]. Recent work has demonstrated an advanced hydrogen passivation technique applicable to silicon solar cells, which can improve the effectiveness of hydrogen passivation by manipulating the charge state of atomic hydrogen [10-12]. It is known that there are three charge states of atomic hydrogen in silicon, namely, the positive $\left(\mathrm{H}^{+}\right)$, negative $\left(\mathrm{H}^{-}\right)$, and neutral $\left(\mathrm{H}^{0}\right)$ charge states [1316]. The ability of hydrogen to assume different charge states has important implications for both diffusion and passivation mechanisms. Recent research has found that hydrogen charge states play an important role in the passivation of some defects, such the neutralisation of dopant atoms $\left(\mathrm{B}^{-}\right.$by $\mathrm{H}^{+}$ and $\mathrm{P}^{+}$by $\left.\mathrm{H}^{-}\right)[17,18]$, the passivation of impurities $\left(\mathrm{Fe}^{+}\right.$by $\mathrm{H}^{-}$) [19], and the permanent deactivation of boron-oxygen complex $\left(\mathrm{BO}^{+}\right.$by $\mathrm{H}^{-}$or $\left.\mathrm{H}^{0}\right)$ [20].

Illumination has been identified as a key factor to advanced hydrogen passivation, as it can manipulate the charge state of atomic hydrogen. It was reported that illumination was a crucial requirement for the permanent deactivation of boron-oxygen (B-O) complex in the regeneration process [21, 22]. Recently, Wilking et al. used a laser with an increased intensity to achieve high-speed regeneration processes for this defect complex [20]. It has also been shown that illumination is able to help achieve advanced hydrogen passivation of upgraded metallurgical grade (UMG) wafers through the generation of the minority charge states of atomic hydrogen [12]. Similarly it was reported that illumination can enhance hydrogen motion in hydrogenated amorphous silicon (a-Si:H) [23]. In this paper we further investigate the use of lasers in advanced hydrogenation processes, particularly in the context of applications to cheaper forms of silicon.

Lasers have been widely used in photovoltaics for a variety of processes such as edge junction isolation [24], 


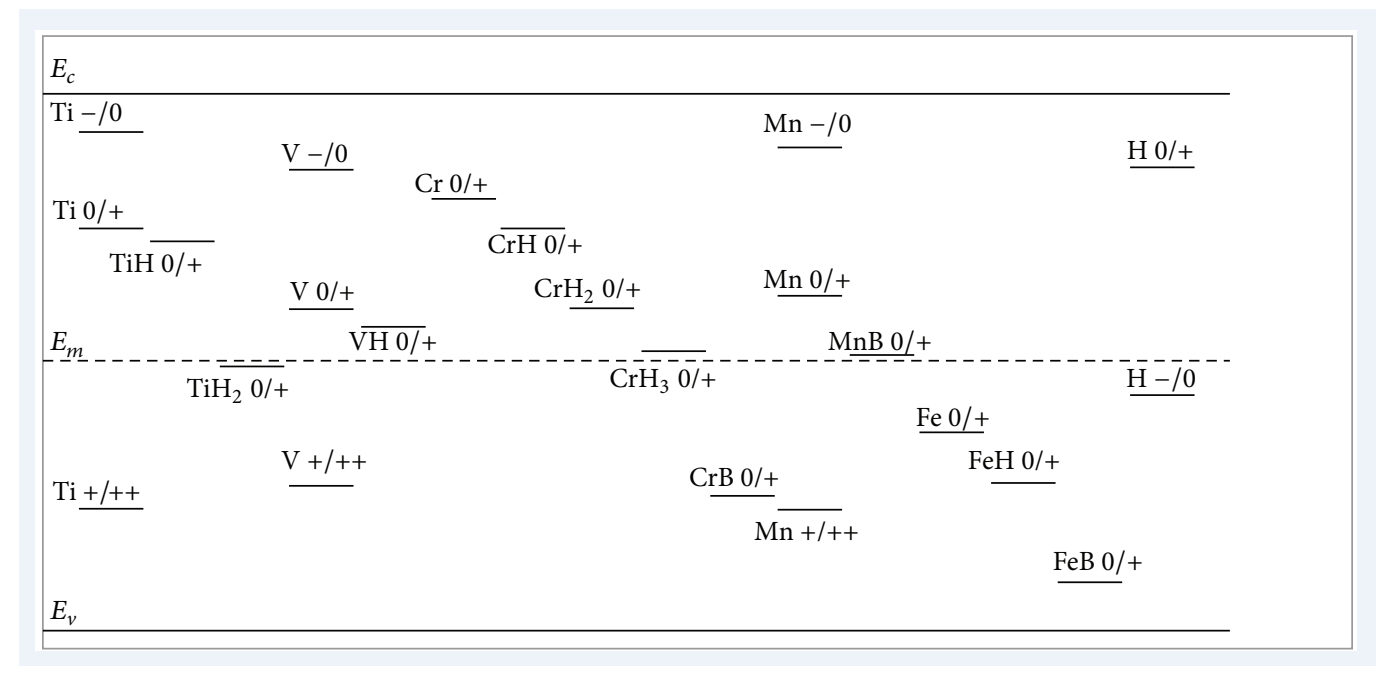

(a)

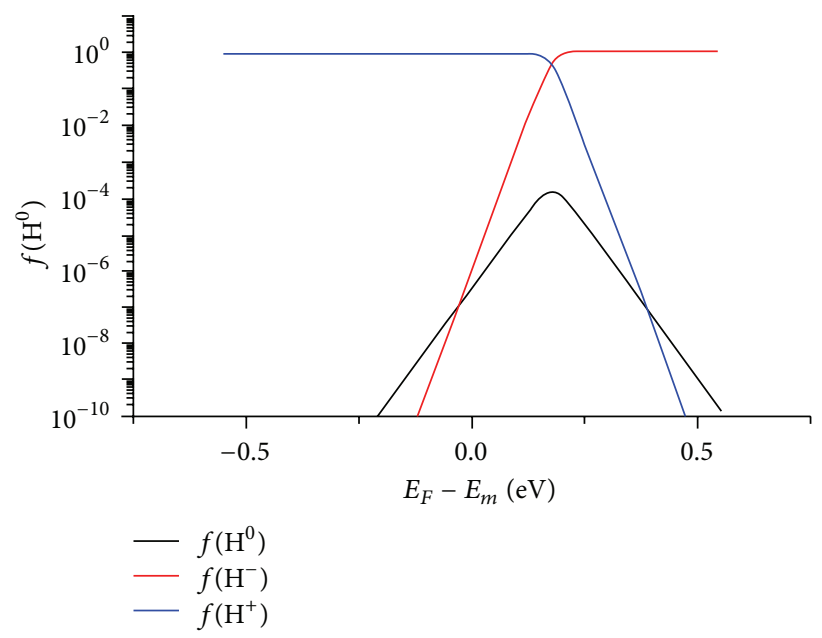

(b)

FIGURE 1: Defect energy levels of transition metal impurities and hydrogen at room temperature without illumination. Donor levels are denoted by $0 /+$, acceptor levels by $-/ 0$, and double donor levels by $+/++[12]$. (b) The fractional concentration of the positive, neutral, and negative charge states of hydrogen at $423 \mathrm{~K}$ as a function of Fermi level [14].

buried contact groove formation [25], selective doping [26], and texturing [27] and for the ablation of dielectric layers [28]. Lasers, as a source of illumination and heating, can provide heat and manipulate the charge states of atomic hydrogen and hence provide an interesting opportunity for performing hydrogen passivation. The localized nature of laser processes could potentially enable hydrogen passivation to be performed only in selected regions of a device. Such localized processes could have various applications in making silicon solar cells, such as achieving the concept of selective emitter formation by locally deactivating and/or activating dopant atoms or passivating localized damaged regions such as dislocation clusters in cast-monocrystalline silicon. The localized nature of this process can also be useful when investigating the specific impact of hydrogenation processes or when attempting to understand the underlying mechanisms. It may also allow hydrogen passivation to be performed subsequent to all other temperature processes. This is significant as hydrogen passivation is not always stable, particularly when cell fabrication involves temperature steps subsequent to the hydrogenation process [2931]. A subsequent high temperature process may reactivate defects, and hence an additional laser enhanced hydrogen passivation may be required to recover the hydrogenation effect.

This paper first introduces the theory of hydrogen charge states followed by a demonstration of the use of lasers to achieve localized hydrogen passivation. The potential detrimental effects of laser enhanced hydrogen passivation process such as the generation of laser induced damage are also explored. The importance of illumination and cooling down rate on the effectiveness of laser enhanced hydrogen passivation is also presented. Finally, the successful application of laser enhanced hydrogen passivation for improving 

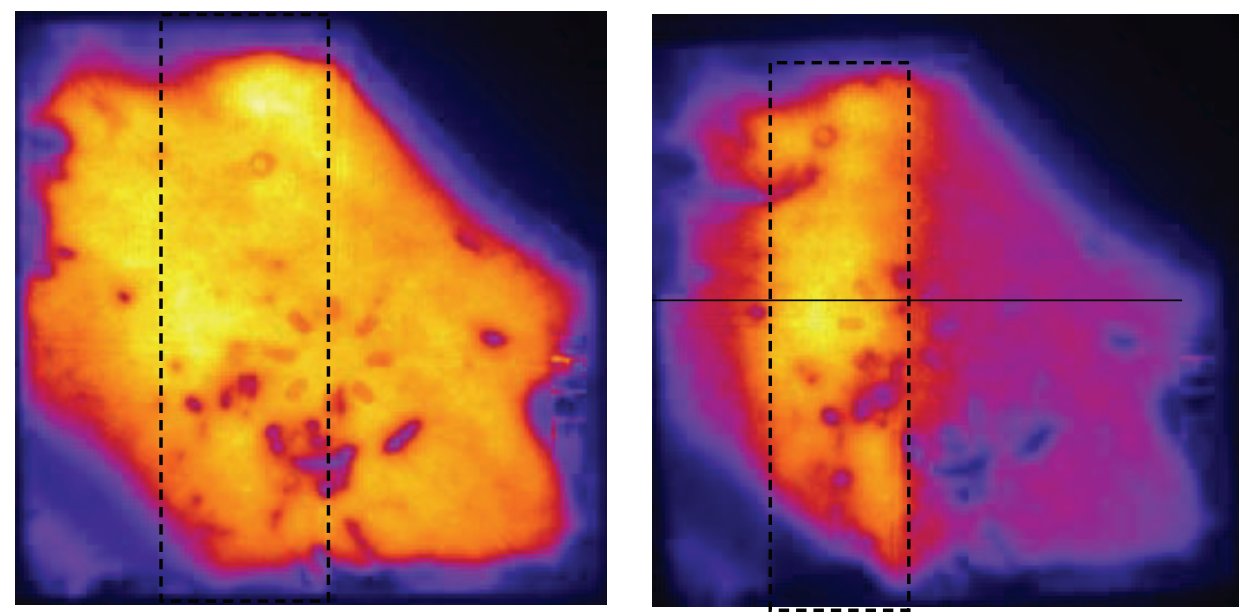

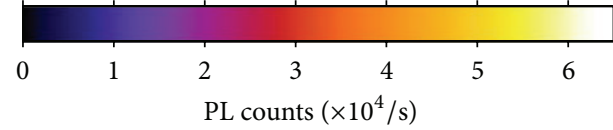

(a)

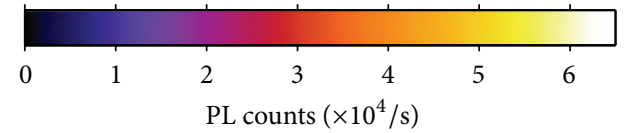

(b)

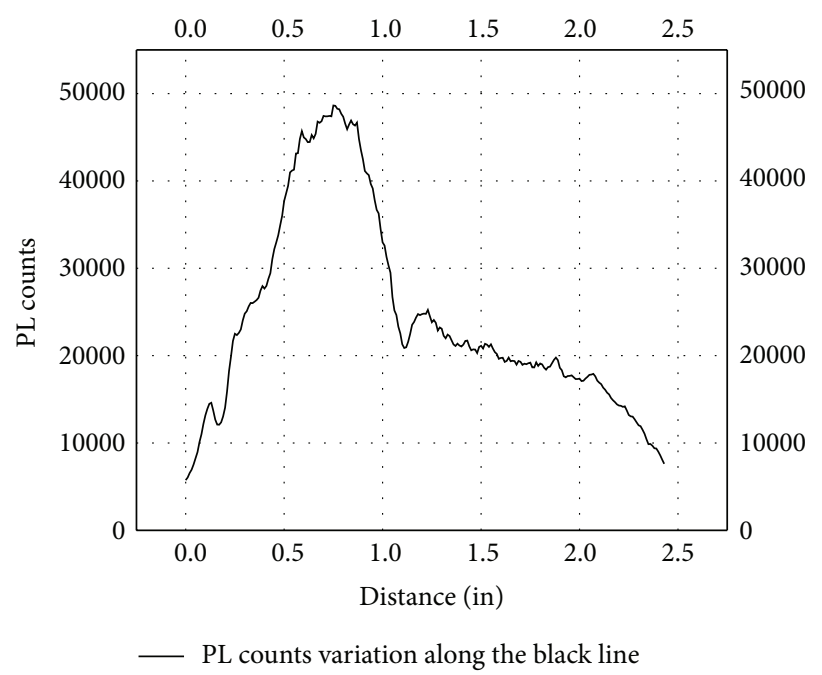

(c)

Figure 2: PL images (a) before and (b) after the laser annealing process for samples with the hotplate held at room temperature, a laser power density of $1.83 \times 10^{3} \mathrm{~W} / \mathrm{cm}^{2}$ with a scan speed of $15 \mathrm{~mm} / \mathrm{s}$. The rectangle indicates the laser processed region. (c) The PL counts along the dark line on image are presented (b). Please note that PL imaging (a) was taken with an exposure time $1 \mathrm{~s}$ and (b) was taken with an exposure time $0.5 \mathrm{~s}$.

the performance of completed cast-monocrystalline silicon solar cells is demonstrated.

\section{Hydrogen Charge State Theory}

It is well established that there are three charge states of atomic hydrogen in crystalline silicon, namely, the positive charge state, negative charge state, and neutral charge state. Hydrogen is reported to have a donor lever at $0.16 \mathrm{eV}$ below the conduction band for the donor level and an acceptor level $0.07 \mathrm{eV}$ below the middle of bandgap [14] as shown in Figure 1(a). Herring et al. predicted that the relative concentration of the hydrogen charge species depends on the position of the Fermi level illustrated in Figure 1(b) [14]. In p-type silicon, the Fermi level is well below the hydrogen acceptor and donor levels; therefore almost all of the interstitial hydrogen is in the positive charge state $\left(\mathrm{H}^{+}\right)$at room temperature. In n-type silicon, the negative hydrogen charge species $\left(\mathrm{H}^{-}\right)$will commonly dominate at the room temperature; however the positive charge state will become dominant at elevated temperatures, with a threshold temperature for this transition determined by the concentration of n-type dopants. The neutral charge state of atomic hydrogen is always a minority hydrogen charge species and is reported to be highly reactive and have very fast self-ionization rate into $\mathrm{H}^{+}[32]$. 


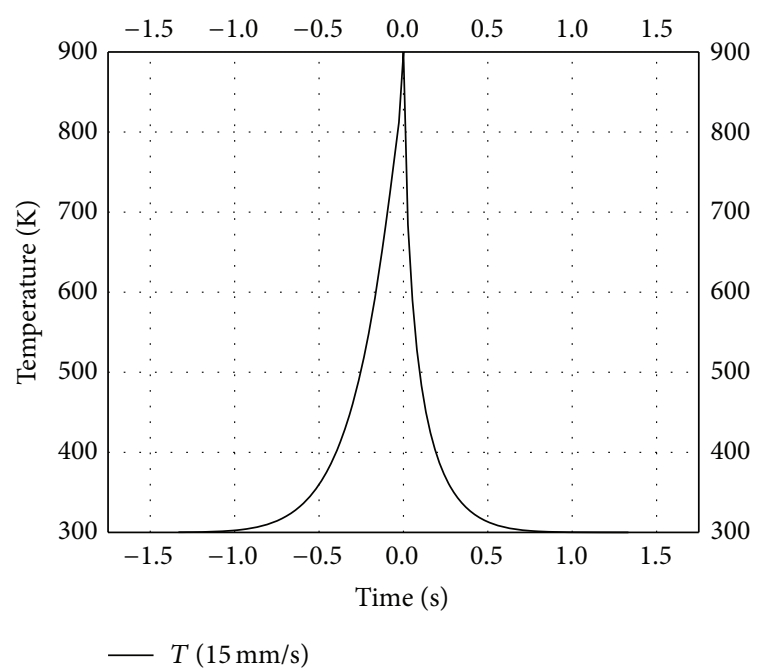

FIgURE 3: The temperature profile of the central point of the sample in Figure 2 with the time simulated by the numerical model. The input parameters were laser scan speed at $15 \mathrm{~mm} / \mathrm{s}$, laser power density at $0.935 \mathrm{~W} / \mu \mathrm{m}$, and substrate temperature at $300 \mathrm{~K}$. The temperature was nearly uniform across the thickness of the sample.

To understand charge states of atomic hydrogen, their properties and transitions are important, as they have a great impact on diffusion and bonding mechanisms. In p-type silicon $\mathrm{H}^{+}$will be trapped by the ionised boron atoms $\left(\mathrm{B}^{-}\right)$ due to the columbic attraction at moderate temperatures [33]. Similarly, the diffusion of $\mathrm{H}^{-}$in n-type silicon will be retarded by interaction with ionised phosphorus atoms $\left(\mathrm{P}^{+}\right)$ [34]. In contrast $\mathrm{H}^{0}$ is unaffected by fixed charges such as ionised dopant atoms and charged defects within silicon. Mathiot reported that the diffusivity of $\mathrm{H}^{0}$ was five orders of magnitude larger than that of $\mathrm{H}^{+}$at $423 \mathrm{~K}$ [35]. Hydrogen bonding with defects is also affected by the charge state of the hydrogen. The donor and acceptor energy levels of several metal impurities and crystallographic defects within silicon have been identified in the literature [36-42]. In Figure 1, the energy levels for some transition metals and for hydrogen are illustrated. It can be seen that many metallic impurities occupy a positive charge state in the p-type wafer, which means that the dominant hydrogen charge state $\left(\mathrm{H}^{+}\right)$ is energetically unfavourable due to columbic repulsion. Furthermore, the passivation of these metallic impurities by $\mathrm{H}^{+}$is made less likely by the lack of available electrons to form a bond. The minority charge states $\left(\mathrm{H}^{0}\right.$ or $\left.\mathrm{H}^{-}\right)$do not encounter such obstacles and may be able to passivate these impurities more effectively.

This has been evidenced by observations that metallic impurities with donor energy levels well above the middle of the bandgap of silicon, such as vanadium (V), chromium $(\mathrm{Cr})$, and manganese $(\mathrm{Mn})$, are not well passivated by hydrogen in p-type silicon using conventional hydrogen passivation techniques [43]. However, in n-type wafers, it is possible to effectively passivate these metallic impurities $[40,44]$, as the concentration of $\mathrm{H}^{0}$ and $\mathrm{H}^{-}$is much higher. Additionally, it is known that the defect energy levels of silicon dangling bonds are distributed continuously across the bandgap, and there are two types of defect energy levels associated with the these dangling bonds, which are donor levels $(0 /+)$ located in the lower part of silicon bandgap and acceptor levels $(-/ 0)$ located in the upper part of silicon bandgap $[45,46]$. In the p-type silicon, the Fermi level is close to the valence band so that most of the dangling bonds are in the positive charge state, which may require the opposite charge state of hydrogen $\left(\mathrm{H}^{-}\right)$to be passivated.

Based on an understanding of the charge states of atomic hydrogen, advanced hydrogen passivation can be achieved through manipulation of these charge states. High temperatures shift the Fermi level towards the middle of the energy bandgap of crystalline silicon and therefore achieve higher ratio of the minority charge states of atomic hydrogen in p-type silicon. Furthermore, higher temperatures increase the diffusivity of hydrogen and the release rate of hydrogen from the hydrogenated silicon nitride $\left(\mathrm{SiN}_{x}: \mathrm{H}\right)$ layer [47-50]. However, high temperature also leads to more rapid dissociation of hydrogen-defect complexes [30], which can limit the effectiveness of high temperature passivation processes. Illumination is another key factor that could dramatically increase the relative concentrations of the minority charge states of atomic hydrogen [12, 51]. For example, in p-type silicon, as more excess minority carriers are generated by illumination, increased concentrations of $\mathrm{H}^{0}$ and $\mathrm{H}^{-}$can be obtained. Additionally, illumination can help reduce the net reactivation of defects during cooling phase of high temperature hydrogen passivation, by retaining the relative concentration of the minority charge species to repassivate thermally dissociated defects [11, 12]. In conclusion, temperature is crucial for hydrogen passivation; however it increases both defect deactivation and dissociation mechanisms and may be limited by many other cell processing requirements [52, 53]. It is therefore hard to optimise for achieving advanced hydrogen passivation. In contrast, illumination can be used to control the ratio of charge states of hydrogen, while having no significant impact on other cell processes, and hence play a key role in advanced hydrogen passivation. As sources of both heat and illumination lasers are an attractive tool for advanced hydrogenation techniques, lasers also enable the option for performing advanced hydrogenation on localised areas of silicon wafers.

\section{The Use of Lasers to Achieve Localized Hydrogen Passivation through a Combination of Light and Heat}

With the right laser and processing conditions, hydrogenation could theoretically be improved on a laser processed area with the appropriate temperature and excess carrier density to maximise the desired minority hydrogen charge state concentrations. In this section, lasers were used to enhance localised hydrogenation for silicon wafers.

3.1. Experimental Details. 5 -inch $0.9 \mathrm{c} \cdot \mathrm{cm}$ p-type Czochralski $(\mathrm{Cz})$ silicon wafers were cut into 2 -inch samples for ease of laboratory processing and then saw damage etched, cleaned, 


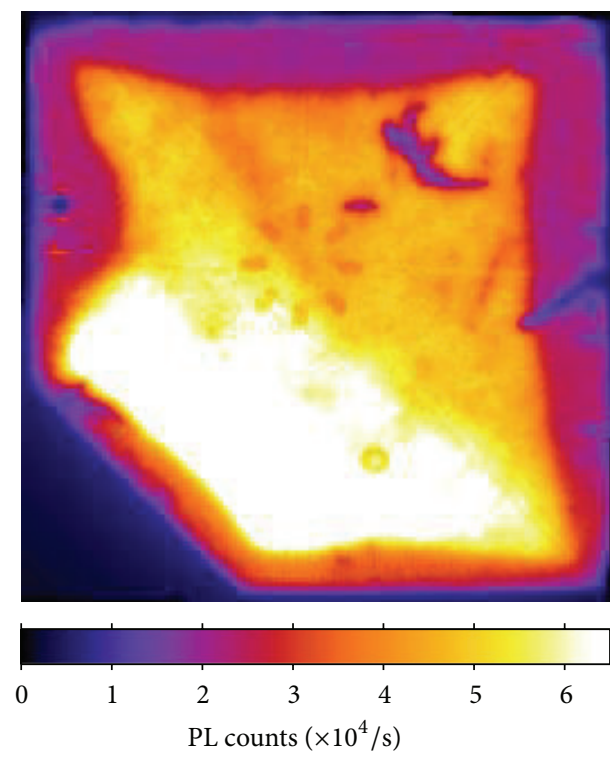

(a)

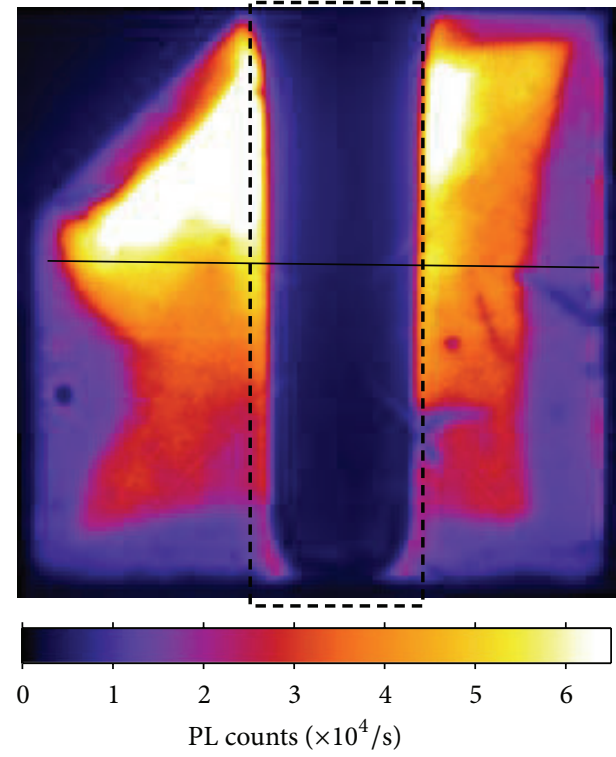

(b)

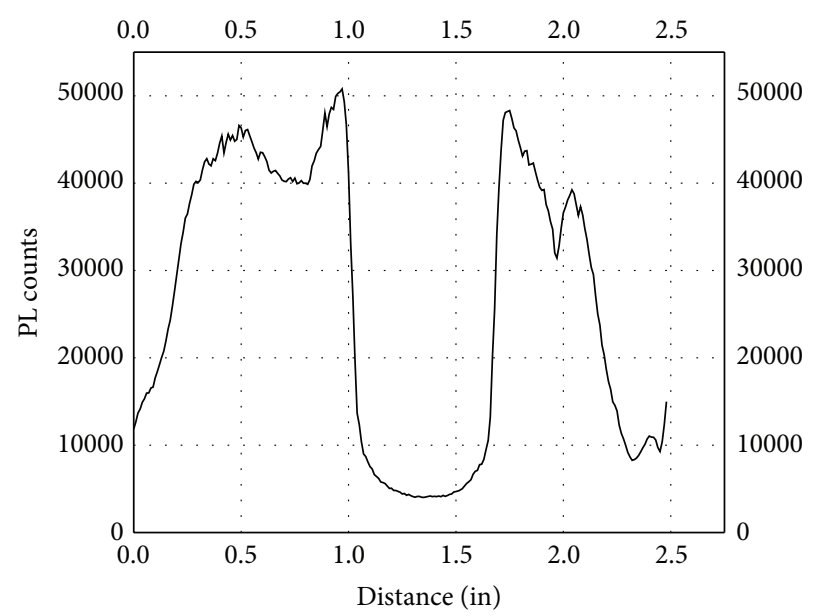

(c)

FIGURE 4: The laser damage shown in PL image before (a) and after (b) the laser annealing process for a laser power density of $4.08 \times 10^{3} \mathrm{~W} / \mathrm{cm}^{2}$ with a scan speed of $6 \mathrm{~mm} / \mathrm{s}$ and a hotplate held at room temperature. The dashed line rectangle indicates the laser processed region. The black line is used to indicate the PL counts distribution across the sample. (c) The PL counts variation along the black line.

and HF dipped. Subsequently, hydrogenated silicon nitride $\left(\mathrm{SiN}_{x}: \mathrm{H}\right)$ films of thickness $75 \mathrm{~nm}$ and refractive index 2.0 were deposited on these silicon samples using a laboratory type Roth \& Rau AK400 plasma enhanced chemical vapour deposition (PECVD) tool. The laser annealing process was conducted by a LIMO laser, which was a line laser operated at continuous wave mode with the wavelength of $808 \mathrm{~nm}$ and power densities ranging from $3.26 \times 10^{2}$ to $4.08 \times 10^{3} \mathrm{~W} / \mathrm{cm}^{2}$. The laser scanned across the center of the sample once using a speed of $15 \mathrm{~mm} / \mathrm{s}$. During the laser hydrogenation process, samples were placed on the hotplate, of which the temperature varied from room temperature to $723 \mathrm{~K}$. Photoluminescence (PL) images were taken using a BTi R1 luminescence imaging tool before and after laser hydrogenation [54].
3.2. Results and Discussion. The effect of the laser hydrogenation process is shown in Figure 2, whereby the wafer was at room temperature. Figures 2(a) and 2(b) show the PL images of the wafer before and after the laser hydrogenation process, respectively. It should be noted that PL images were taken at the exposure times $1 \mathrm{~s}$ and $0.5 \mathrm{~s}$ before and after laser annealing, respectively, so that the PL counts of (b) were physically halved compared to those of (a). The PL images indicated that the PL response of the laser processed region increased after the laser annealing process, which was due to localised hydrogen passivation. PL response was positively correlated with the effective lifetime, and therefore an increased PL response of a given sample suggested an increase in the effective lifetime of the material [55]. It was expected that the temperature and excess minority carriers generated by laser 
would increase the ratio of desired minority charge states of atomic hydrogen, leading to a higher effectiveness of hydrogen passivation in the laser processed region. However, some low PL response regions could be seen in the laser processed region that was due to laser induced damage. Additionally, the PL response of the rest of the sample was reduced a bit after the laser treatment. From the plot of PL counts along the black line illustrated in Figure 2(c), the average PL counts in the laser processed region were more than double of the PL counts in the adjacent region. This further supported that localised hydrogen passivation occurred.

To understand the mechanisms underlying the localised hydrogen passivation effect, a thermal model was used to explain the PL response enhancement. The numerical simulated model was built on the basis of finite element methods and aimed to link the optical excitation with the thermal effect and the consequent hydrogenation effect [56]. For solving the complex heat transfer equations during the laser annealing process, a numerical approach was adopted, in which case the laser power, scan speed, and the substrate temperature were set as the input parameters and each heat transfer equation was first discretised into small steps and then integrated. The temperature-time profile of the central point of the sample during laser enhanced hydrogen passivation is demonstrated in Figure 3; the induced peak temperature could reach $900 \mathrm{~K}$, which was within the optimal temperature range for hydrogen passivation by conventional hydrogenation techniques $[57,58]$.

While it has been demonstrated that localized hydrogen passivation can be enhanced through the use of a laser, it is important to carefully control the laser power. Figure 4 illustrates the effect of annealing with a laser power density of $4.08 \times 10^{3} \mathrm{~W} / \mathrm{cm}^{2}$. The laser processed area appeared as a dark rectangle across the sample, indicating that laser damage was induced in this region. The peak temperature of the sample in this case is illustrated in Figure 5. It was found that the peak temperature of the sample can reach $2200 \mathrm{~K}$, which was much more than the melting temperature of silicon at $1687 \mathrm{~K}$. The damage may therefore be due to the phase transformation of silicon from solid to liquid such that the expanded volume of silicon can fracture the silicon nitride layer $[59,60]$. It may therefore be concluded that high laser power densities such as $4.08 \times 10^{3} \mathrm{~W} / \mathrm{cm}^{2}$ could lead to the formation of laser damage.

The laser annealing process conducted at a laser power density of $3.26 \times 10^{2} \mathrm{~W} / \mathrm{cm}^{2}$ and hotplate temperature $723 \mathrm{~K}$ was illustrated in Figure 6. No localized hydrogen passivation was observed, as the heat and excess minority carriers generated at this laser power level were not sufficient to induce enough minority charge states of hydrogen. However, a substantial improvement in lifetime was achieved through the conventional hydrogen passivation of the sample.

The temperature-time profile of this sample was shown in Figure 7. In this case, the peak temperature reached $830 \mathrm{~K}$, which was quite close to the steady state temperature of the sample at $723 \mathrm{~K}$. This temperature difference and corresponding laser generated minority carriers were not sufficient enough to induce any localized hydrogen passivation.

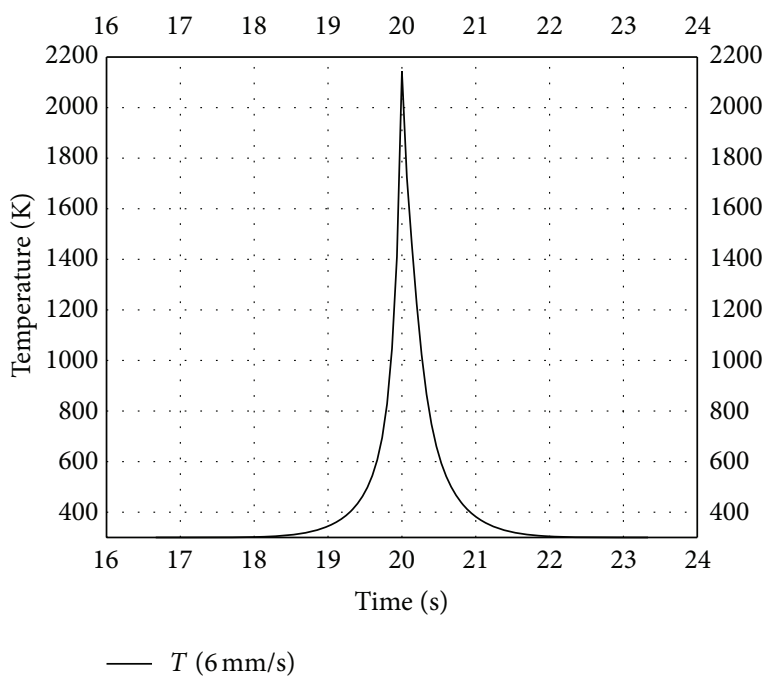

FIGURE 5: The temperature profile of the central point of the sample in Figure 4 with the time simulated by the numerical model. The input parameters were laser scan speeds at $6 \mathrm{~mm} / \mathrm{s}$, laser power densities at $4.08 \times 10^{3} \mathrm{~W} / \mathrm{cm}^{2}$, and substrate temperatures at $300 \mathrm{~K}$. The temperature was nearly uniform across the thickness of the sample.

\section{The Importance of Illumination and Cooling Rates on Laser Enhanced Hydrogen Passivation}

It has been demonstrated that laser is capable of achieving localized enhanced hydrogen passivation. However, it is still a matter of debate as to whether it is the laser induced heat or the generation of excess carriers that determines the performance of the localized hydrogen passivation. Many papers have discussed the effect of temperature on hydrogen passivation, which mainly focus upon the competing processes of hydrogen incorporation and the retention of hydrogen within the silicon wafer $[3,4,61]$; however it is also known that illumination may enhance the effectiveness of hydrogen passivation even at high temperatures [9].

In this section, another important factor, the thermal gradient of the sample under illumination, is also investigated on the performance of laser enhanced hydrogen passivation.

4.1. Experimental Details. p-type UMG wafers purified using the PHOTOSIL process [62] were used in this experiment. These wafers were cleaned and then coated on both sides with silicon oxynitride $\left(\mathrm{SiO}_{x} \mathrm{~N}_{y}\right)$. Half of samples were prefired at $973 \mathrm{~K}$ in a belt furnace to predistribute atomic hydrogen throughout the bulk. The other half of the samples had no prefiring treatment. All wafers were then annealed on a hotplate with the left half of the sample on the hotplate and the right half off the hotplate. The samples were illuminated with $808 \mathrm{~nm}$ wavelength illumination, with photon fluxes between $1.2 \times 10^{17}$ and $1.7 \times 10^{18}$ photons $/ \mathrm{cm}^{2} / \mathrm{s}$. 


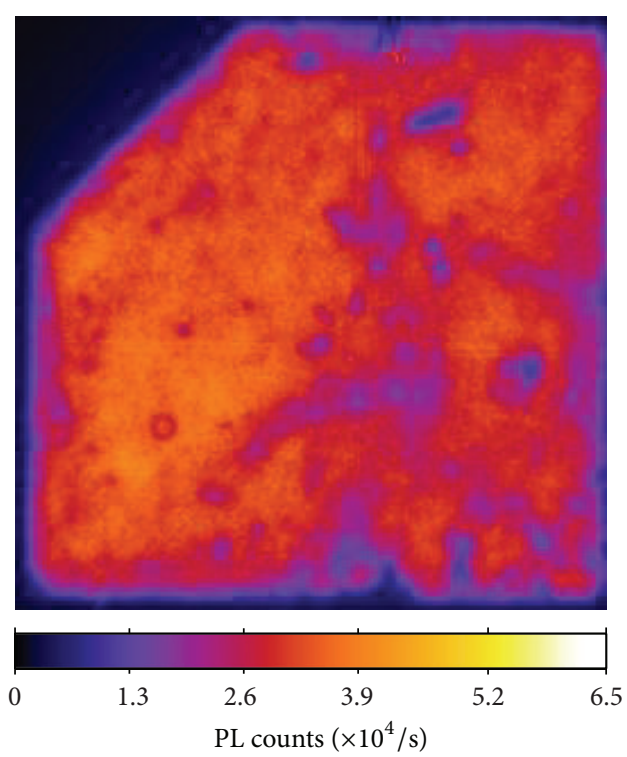

(a)

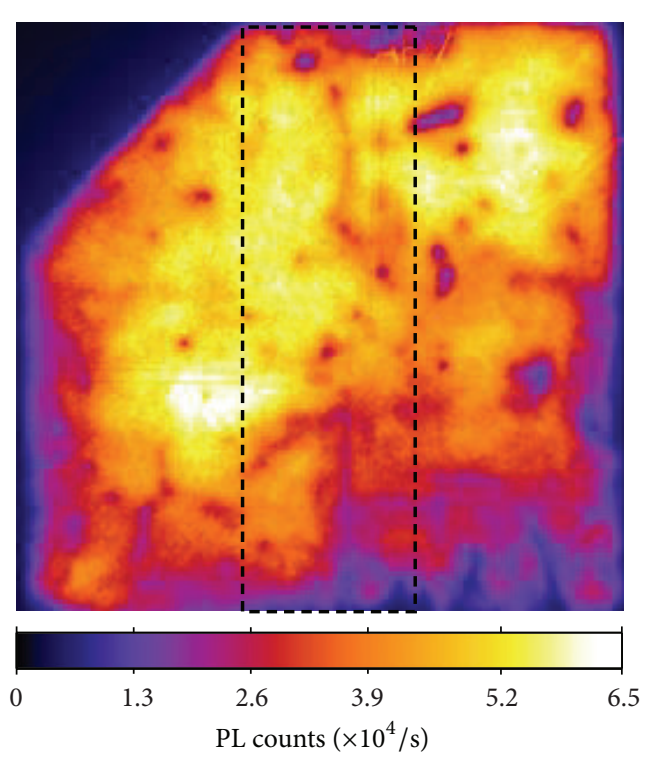

(b)

FiguRE 6: The PL image before (a) and after (b) the laser annealing process for a laser power density of $3.26 \times 10^{2} \mathrm{~W} / \mathrm{cm}^{2}$ with a scan speed of $15 \mathrm{~mm} / \mathrm{s}$ and a hotplate held at $723 \mathrm{~K}$. The dashed line rectangle indicates the laser processed region.

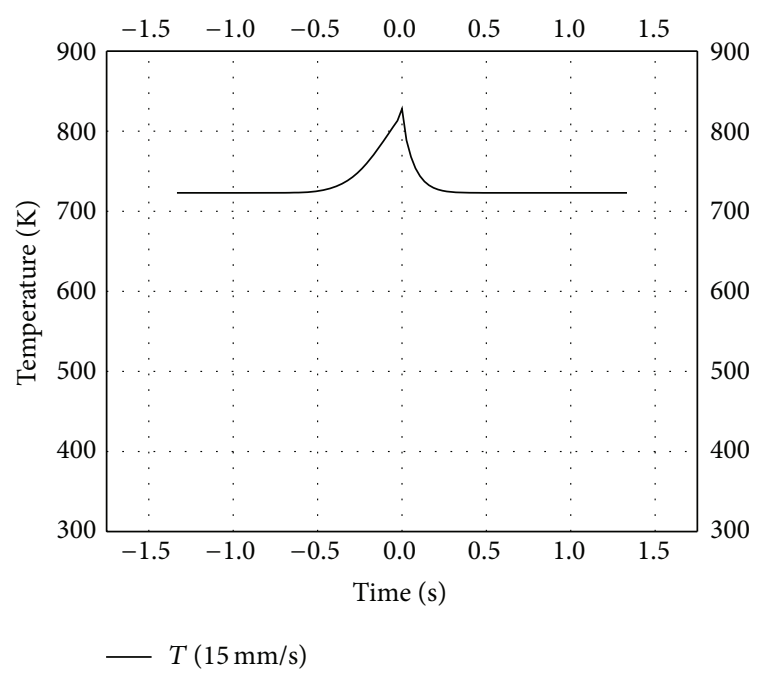

FIGURE 7: The temperature profile of the centre of the sample illustrated in Figure 6 during the laser annealing process. It was conducted when laser power density was $3.26 \times 10^{2} \mathrm{~W} / \mathrm{cm}^{2}$, a scan speed was $15 \mathrm{~mm} / \mathrm{s}$, and a hotplate was held at $723 \mathrm{~K}$.

4.2. Results and Discussion. The PL responses for samples with a thermal gradient are illustrated in Figure 8. While there was no significant response to the lowest laser intensity the response to the higher laser intensities was clearly highlighted. It may be observed that the half of the sample off the hotplate had much better PL responses than the half of the sample on the hotplate for the higher laser intensities. This may be due to the different cooling rates. The half off the hotplate cooled more rapidly and from a lower temperature, which effectively prevented the dissociation of hydrogen-defect complexes by reducing the duration of time that the temperature was still high enough to reactivate defects. UMG wafers with a prefiring process had better PL responses than the UMG wafers without a prefiring process, as the hydrogen had already been distributed across the sample. For the UMG wafers without prefiring process, the $\mathrm{PL}$ response enhanced regions were close to the edge of the hotplate, as these regions were at higher temperature, and hence more hydrogen could be released. At the same time, these regions still maintained the rapid cooling rate as they were off the hotplate. It was therefore concluded that rapid cooling rates and high illumination intensity are beneficial for advanced hydrogenation effects.

\section{Laser Enhanced Hydrogen Passivation on the Complete Cast-Monocrystalline Silicon Solar Cell}

So far it has been demonstrated that laser enhanced hydrogen passivation can dramatically improve the electronic quality of the silicon wafers. Here this technique is adopted for further enhancing the performance of finished cells made on castmonocrystalline silicon wafers. The postfabrication nature of this process enables it to be easily applied to any type of cell with a hydrogen source layer.

5.1. Experimental Details. Complete screen-printed castmonocrystalline silicon solar cells were fabricated for this experiment. The cast-monocrystalline silicon wafers were textured, followed with standard screen printing phosphorus diffusion and one-hour low temperature diffusion at $1023 \mathrm{~K}$, then coated with single side $\mathrm{SiN}_{x}: \mathrm{H}$ film of refractive index 


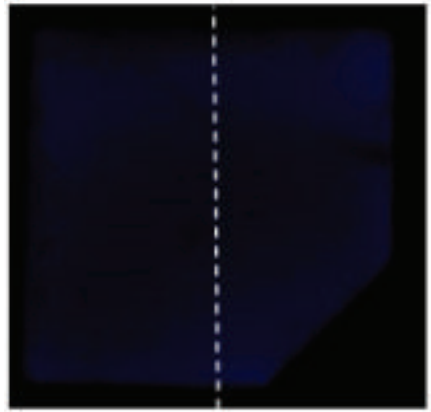

(a)

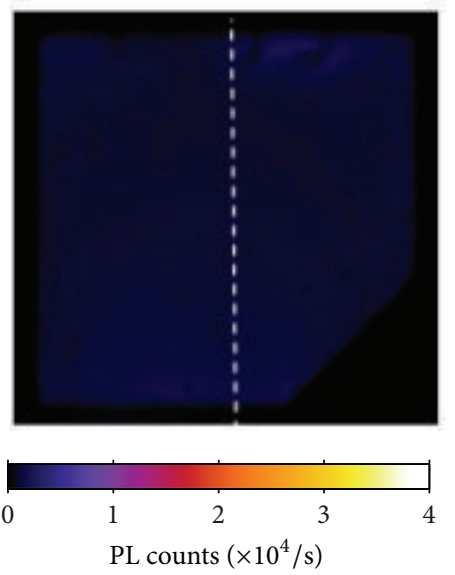

(b)

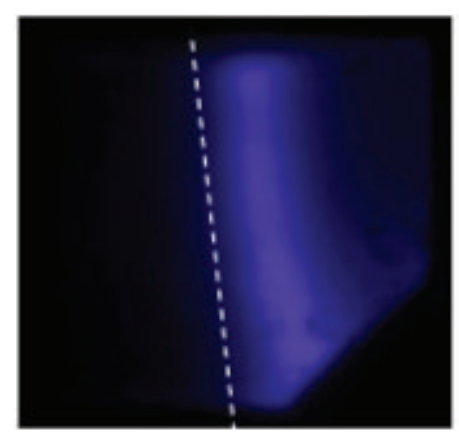

(c)

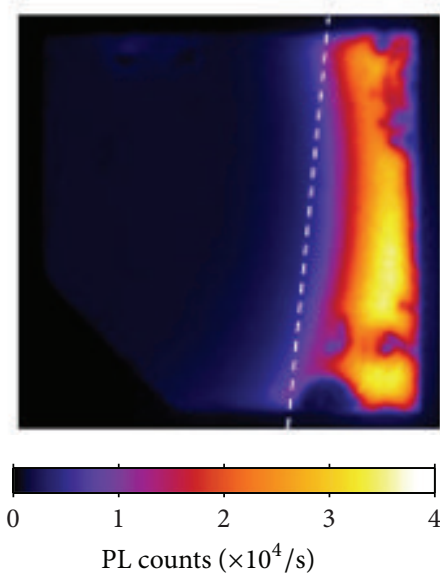

(d)

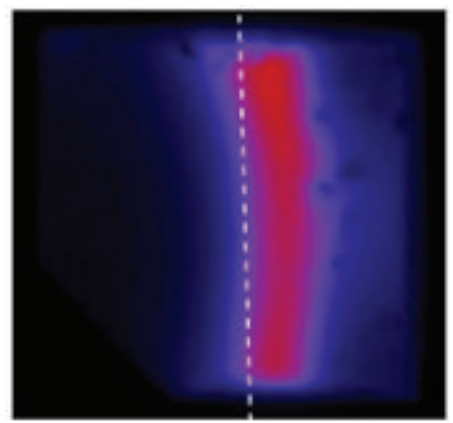

(e)

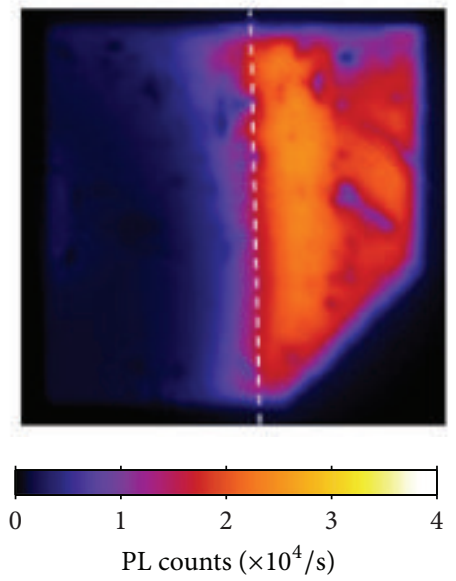

(f)

FIGURE 8: PL images of samples after illuminated annealing. Top wafers (a, c, and e) were as deposited with no prefiring process. Bottom wafers (b, d, and f) were prefired at $973 \mathrm{~K}$ in belt furnace to activate hydrogen and distribute it throughout the bulk. First column wafers (a and $\mathrm{b}$ ) were illuminated with the photon flux of $1.2 \times 10^{17}$ photons $/ \mathrm{cm}^{2} / \mathrm{s}$. Second column wafers ( $\mathrm{c}$ and d) were illuminated with $9 \times 10^{17}$ photons $/ \mathrm{cm}^{2} / \mathrm{s}$. And third column wafers (e and f) were illuminated with $1.7 \times 10^{18}$ photons $/ \mathrm{cm}^{2} / \mathrm{s}$. For each sample, the left half of the sample was heated on the hot plate, while the right half was off the hot plate.

2 and thickness $75 \mathrm{~nm}$ deposited at $673 \mathrm{~K}$, and finally screenprinted with metal contacts. Laser enhanced hydrogen passivation was conducted by a system equipped with hotplate and laser. In the experiment, the temperature of the hotplate was set to be $623 \mathrm{~K}$ and the laser illumination intensities were varied from $6.12 \times 10^{18}$ to $9.6 \times 10^{18}$ photons $/ \mathrm{cm}^{2} / \mathrm{s}$. The performance of the complete cast-monocrystalline silicon solar cells was characterised before and after the laser enhanced hydrogen passivation through the generation of light/dark $I-V$ curves, quantum efficiency curves, light beam induced current (LBIC) map [63], and PL images.

5.2. Results and Discussion. The performance of the complete cast-monocrystalline silicon solar cell was dramatically improved after the laser enhanced hydrogen passivation with an increase in open circuit voltage and short circuit current density, resulting in an absolute efficiency improvement of $0.6 \%$. The light $I-V$ curves before and after laser enhanced hydrogen passivation for the most improved cell are illustrated in Figure 9. The open circuit voltage of the

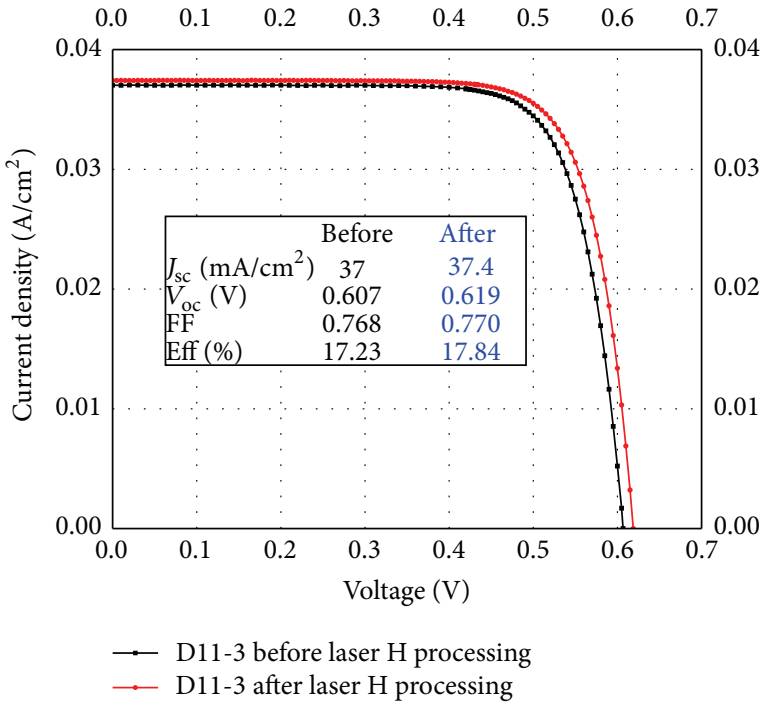

FIGURE 9: Light $I-V$ curves of the complete cast-monocrystalline silicon solar cell before and after laser enhanced hydrogen passivation. 
TABLE 1: The performance variations of finished cast-monocrystalline silicon solar cells before and after laser enhanced hydrogen passivation.

\begin{tabular}{|c|c|c|c|c|}
\hline $\begin{array}{l}\text { Illumination intensity } \\
\text { (photons } / \mathrm{cm}^{2} / \mathrm{s} \text { ) }\end{array}$ & $\begin{array}{c}\text { Efficiency variation } \\
(\%)\end{array}$ & $\begin{array}{c}\text { Open circuit } \\
\text { voltage variation } \\
(\mathrm{V})\end{array}$ & $\begin{array}{c}\text { Short circuit } \\
\text { current variation } \\
\left(\mathrm{mA} / \mathrm{cm}^{2}\right)\end{array}$ & $\begin{array}{l}\text { Fill factor variation } \\
(\%)\end{array}$ \\
\hline $6.1 * 10^{18}$ & $\Delta 0.22$ & $\Delta 0.006$ & $\Delta 0.13$ & $\Delta-0.19$ \\
\hline $7.2 * 10^{18}$ & $\Delta 0.34$ & $\Delta 0.012$ & $\Delta 0.21$ & $\Delta-0.49$ \\
\hline $9.6 * 10^{18}$ & $\Delta 0.40$ & $\Delta 0.004$ & $\Delta 0.23$ & $\Delta 0.96$ \\
\hline $9.6 * 10^{18}$ & $\Delta 0.61$ & $\Delta 0.012$ & $\Delta 0.44$ & $\Delta 0.30$ \\
\hline
\end{tabular}

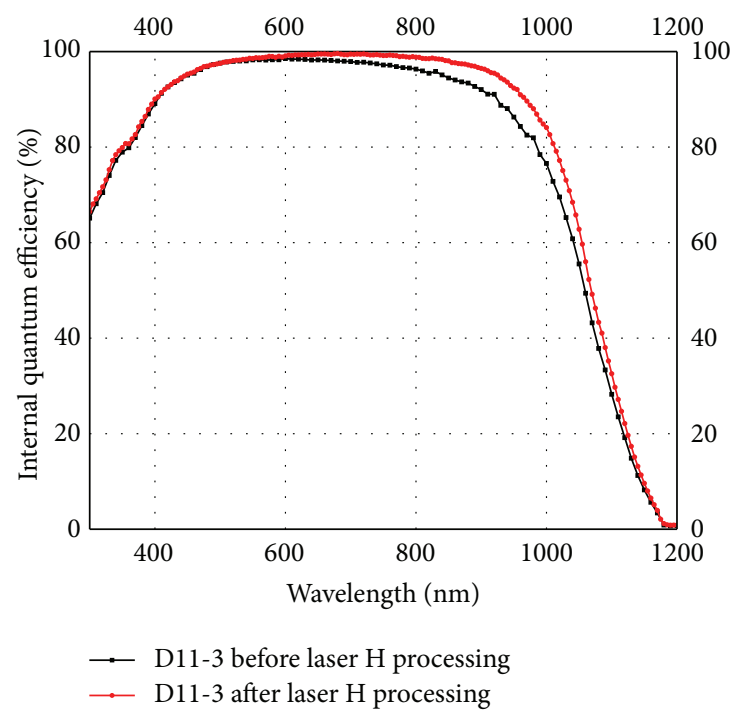

(a)

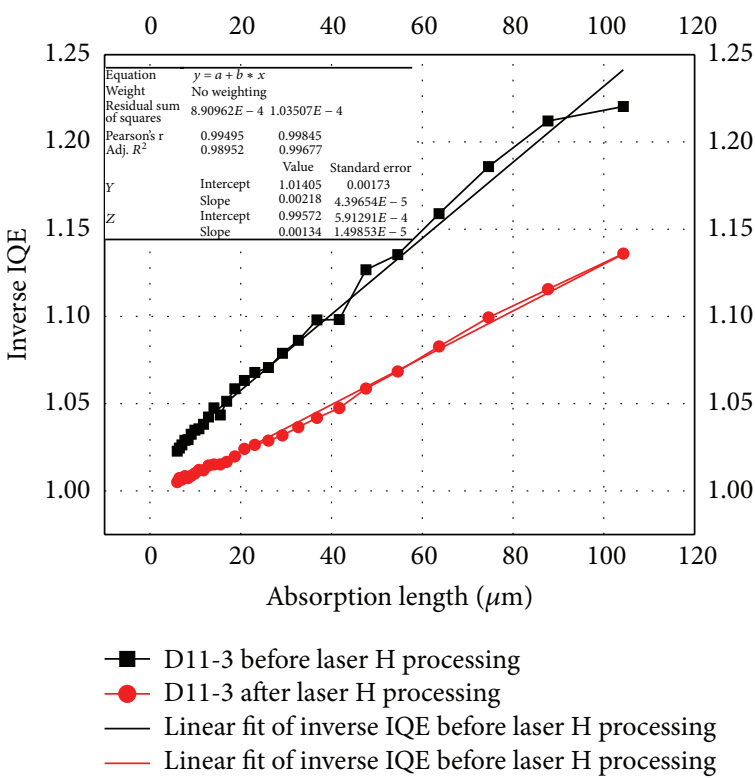

(b)

FIGURE 10: (a) The internal quantum efficiency curve of the cast-monocrystalline silicon solar cells before and after laser enhanced hydrogen passivation. (b) The plot of inverse IQEs as a function of absorption length for the wavelength from $800 \mathrm{~nm}$ to $1000 \mathrm{~nm}$.

cell increased from 0.607 to $0.619 \mathrm{~V}$ and the short circuit current density increased from 37.0 to $37.4 \mathrm{~mA} / \mathrm{cm}^{2}$, leading to an efficiency enhancement from $17.23 \%$ to $17.84 \%$. It should be noted that efficiency enhancements occurred for all the processed cast-monocrystalline silicon solar cells, and the performance variations are listed in Table 1.

The open circuit voltage enhancement resulted primarily from an improved diffusion length of excess minority carriers in the bulk. This was confirmed by the internal quantum efficiency (IQE) curve shown in Figure 10(a). In Figure 10(a), the internal quantum efficiency response increased from $600 \mathrm{~nm}$ to $1100 \mathrm{~nm}$ after the laser enhanced hydrogen passivation. It was due to the fact that laser enhanced hydrogen passivation might increase the desired charge states of hydrogen $\left(\mathrm{H}^{0}\right.$ or $\mathrm{H}^{-}$) converting from $\mathrm{H}^{+}$that has already been distributed across the sample in the screen printing firing process. This could allow further passivation of defects that were not well passivated by $\mathrm{H}^{+}$or reactivated during cooling from high temperatures.

A plot of the inverse IQE as a function of absorption length is shown in Figure 10(b). It was found that the diffusion length of minority carriers increased from $459 \mu \mathrm{m}$ to $746 \mu \mathrm{m}$ after laser enhanced hydrogen passivation according to the equation [64]

$$
\frac{1}{\mathrm{IQE}}=1+\frac{\cos \theta}{\alpha L_{\mathrm{eff}}} .
$$

The superior passivation of bulk silicon material could be further supported by the enhanced spatial internal quantum efficiency map conducted by a $981 \mathrm{~nm}$ laser illustrated in Figure 11. It can clearly be observed in Figures 11(a) and 11(b) that the internal quantum efficiency of these dislocation clusters was improved. Investigation insight into this effect demonstrated that laser enhanced hydrogen passivation can result in superior passivation of dislocation clusters.

It was known that dislocation clusters contained large amount of dangling bonds, with defect energy levels distributed continuously across the silicon bandgap. Dislocations with donor levels in the upper half of the bandgap would be positively charged in p-type silicon without illumination and as such would not be effectively passivated by $\mathrm{H}^{+}$. 


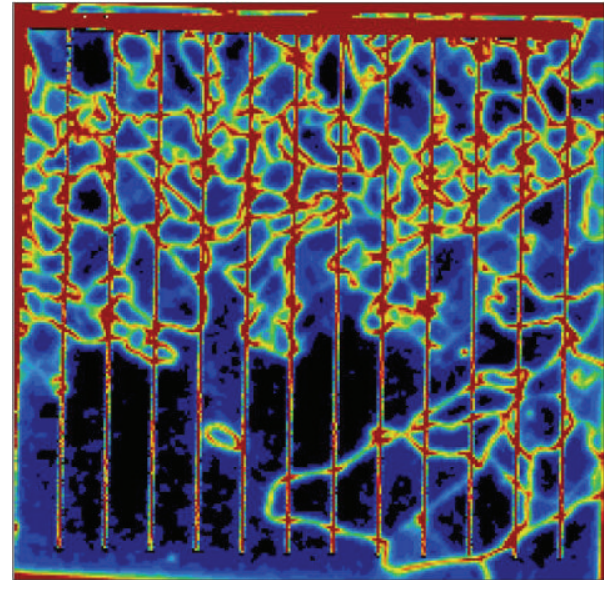
$61 \%$

(a)

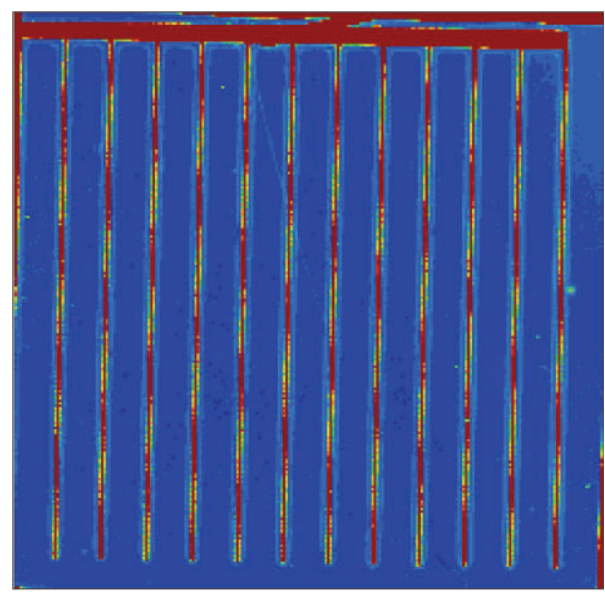

$57 \%$

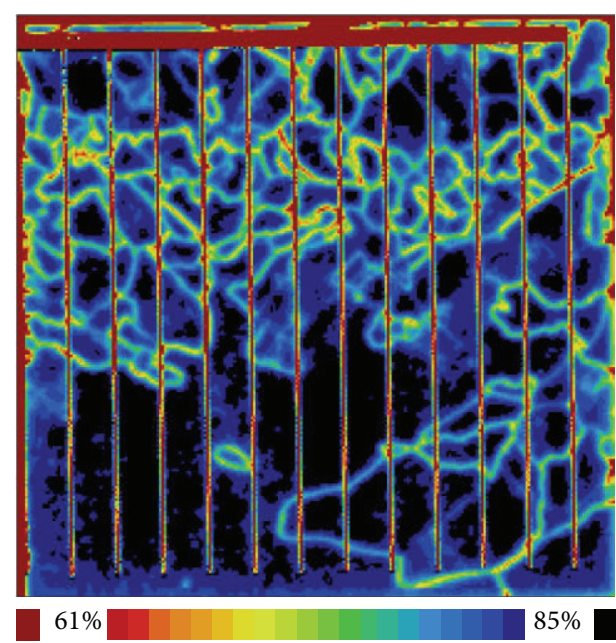

(b)

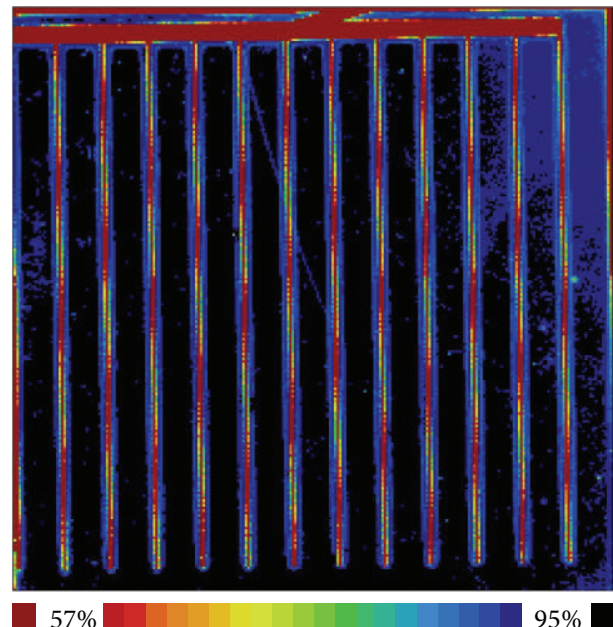

(d)

FIGURE 11: The $981 \mathrm{~nm}$ spatial internal quantum efficiency maps of the cell before (a) and after (b) laser enhanced hydrogen passivation and the $404 \mathrm{~nm}$ spatial internal quantum efficiency maps of the cell before (c) and after (d) laser enhanced hydrogen passivation.

Using laser enhanced passivation large concentrations of excess minority carriers were generated and thereby the concentration of desired hydrogen charge species $\mathrm{H}^{-}$and $\mathrm{H}^{0}$ was increased, which, in theory, could bond more effectively with these positively charged dangling bonds. However, whether $\mathrm{H}^{-}$or $\mathrm{H}^{0}$ was involved in the chemical bonding mechanisms with those nonpassivated dislocation clusters required further investigation.

PL imaging was also used to monitor the lifetime variation of the cell before and after the laser enhanced hydrogen passivation. In Figure 12, it could be observed that the PL response had been dramatically increased after laser enhanced hydrogen passivation, indicating that the effective lifetime of the cell was improved. Furthermore, it can be seen that the feature of dislocation clusters in the PL image had been dramatically reduced, providing further evidence that dislocation clusters can be effectively passivated by laser enhanced hydrogen passivation.

\section{Conclusion}

In this paper, it was demonstrated that laser enhanced hydrogenation led to increased efficiency on finished cells. After laser enhanced hydrogen passivation, the open circuit voltage and short circuit current density of the cast-monocrystalline silicon solar cell were increased, leading to an absolute efficiency enhancement of $0.6 \%$. Detailed investigations indicated that the performance enhancement was mainly attributable to the superior passivation of dislocation clusters in the bulk of the cell. It was believed that the increased $\mathrm{H}^{-}$ or $\mathrm{H}^{0}$ from laser illumination was responsible for the further passivation of those positively charged dangling bonds within the dislocation clusters. It should be emphasized that this process has not yet been fully optimized and further efficiency enhancements might be possible.

Localized laser enhanced hydrogen passivation has also been demonstrated. It was found that the proper laser annealing process could improve the PL response of the laser 


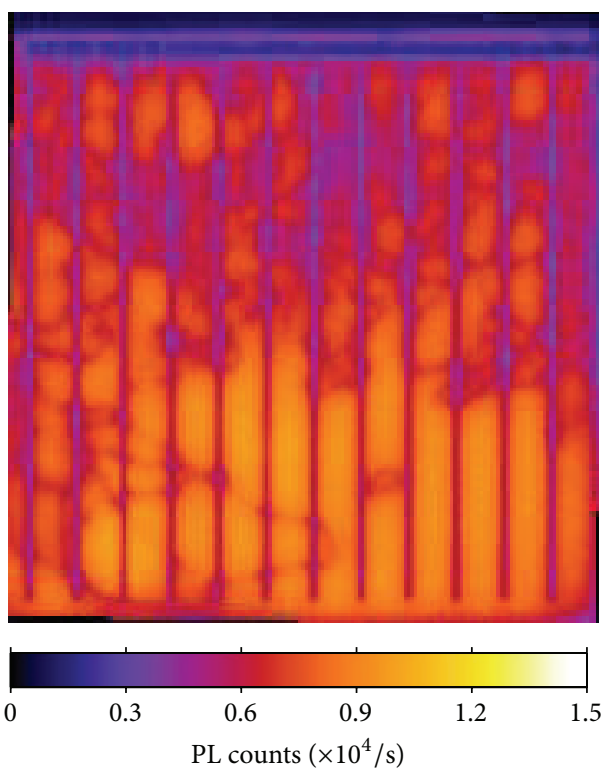

(a)

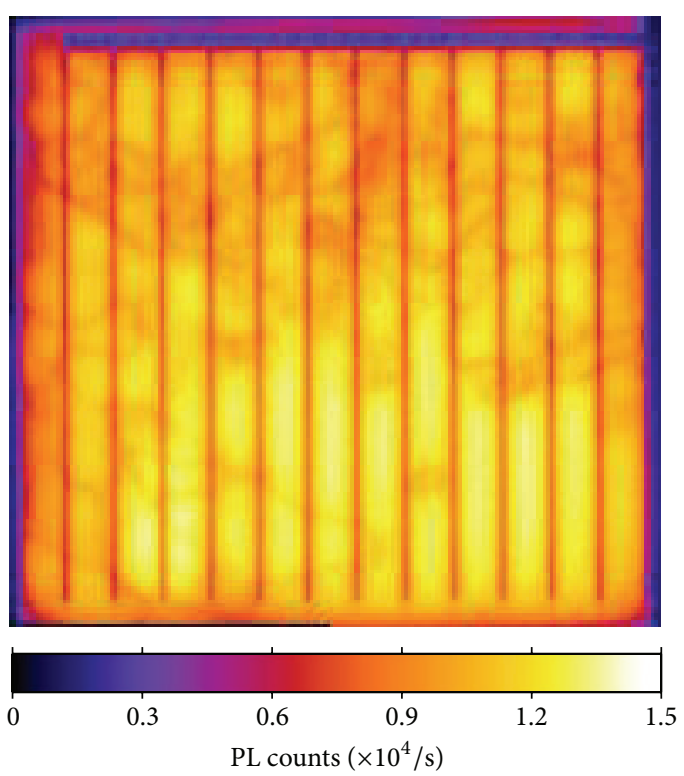

(b)

FIgURE 12: The PL responses of the complete cast-monocrystalline silicon solar cell before and after laser enhanced hydrogen passivation.

processed area. The simulated temperature profile indicated that the optimal temperature for laser annealing process was around $900 \mathrm{~K}$. However, it was also found that improper laser annealing process with the laser power density above $4.08 \times 10^{3} \mathrm{~W} / \mathrm{cm}^{2}$ was likely to induce laser damage due to the mismatch between the thermal expansion coefficients of $\mathrm{Si}$ and $\mathrm{SiN}_{x}: \mathrm{H}$. Furthermore, it was revealed that localised hydrogen passivation would only occur when the laser power density was above a certain threshold value, which in this case was $3.26 \times 10 \mathrm{~W} / \mathrm{cm}^{2}$.

The impact of illumination and cooling down rates on laser enhanced hydrogen passivation was also discussed in this paper. From the literature, illumination was reported to be of significant importance in enhancing the effectiveness of hydrogen passivation, as it could increase the concentration of desired minority charge states of hydrogen that had higher diffusivity and priority in bonding with certain defects, which were also charged and hardly passivated by the dominant hydrogen charge species. Rapid cooling rate was also found to help maintain the effect of advanced hydrogen passivation, as it can prevent the dissociation of hydrogen-defect complexes by reducing the duration of time that the temperature was still hot to reactivate defects.

\section{Conflict of Interests}

The authors declare that there is no conflict of interests regarding the publication of this paper.

\section{Acknowledgments}

The authors would like to acknowledge the Australian Government through the Australian Renewable Energy Agency
(ARENA) for the financial assistance. ARENA is supporting Australian research and development in solar photovoltaic and solar thermal technologies to help solar power become cost competitive with other energy sources. The views expressed herein are not necessarily the views of the Australian Government, and the Australian Government does not accept responsibility for any information or advice contained herein. The authors would also like to thank Jonathon Dore for the assistance of LIMO laser.

\section{References}

[1] J. Kraiem, B. Drevet, F. Cocco et al., "High performance solar cells made from $100 \%$ umg silicon obtained via the photosil process," in Proceedings of the 35th IEEE Photovoltaic Specialists Conference (PVSC '10), pp. 1427-1431, June 2010.

[2] G. del Coso, C. del Cañizo, and W. C. Sinke, "The impact of silicon feedstock on the PV module cost," Solar Energy Materials and Solar Cells, vol. 94, no. 2, pp. 345-349, 2010.

[3] F. Duerinckx and J. Szlufcik, "Defect passivation of industrial multicrystalline solar cells based on PECVD silicon nitride," Solar Energy Materials and Solar Cells, vol. 72, no. 1-4, pp. 231246, 2002.

[4] C. H. Seager and D. S. Ginley, "Studies of the hydrogen passivation of silicon grain boundaries," Journal of Applied Physics, vol. 52, no. 2, pp. 1050-1055, 1981.

[5] J. L. Benton, C. J. Doherty, S. D. Ferris, D. L. Flamm, L. C. Kimerling, and H. J. Leamy, "Hydrogen passivation of point defects in silicon," Applied Physics Letters, vol. 36, no. 8, pp. 670671, 1980.

[6] A. A. Istratov, T. Buonassisi, M. D. Pickett, M. Heuer, and E. R. Weber, "Control of metal impurities in 'dirty' multicrystalline silicon for solar cells," Materials Science and Engineering B, vol. 134, no. 2-3, pp. 282-286, 2006. 
[7] A. G. Aberle, "Overview on SiN surface passivation of crystalline silicon solar cells," Solar Energy Materials and Solar Cells, vol. 65, no. 1-4, pp. 239-248, 2001.

[8] M. Rinio, A. Yodyungyong, S. Keipert-Colberg, D. Borchert, and A. Montesdeoca-Santana, "Recombination in ingot cast silicon solar cells," Physica Status Solidi (A), vol. 208, no. 4, pp. 760-768, 2011.

[9] D. Kohler, A. Zuschlag, and G. Hahn, "On the origin and formation of large defect clusters in multicrystalline silicon solar cells," Solar Energy Materials and Solar Cells, vol. 120, pp. 275-281, 2014.

[10] S. R. Wenham, P. G. Hamer, B. J. Hallam et al., "Advanced hydrogenation of silicon solar cells," Google Patents WO2013173867 A1, PCT/AU2013/000,528, N.I.P., 2013.

[11] B. J. Hallam, P. G. Hamer, S. R. Wenham et al., "Advanced bulk defect passivation for silicon solar cells," IEEE Journal of Photovoltaics, vol. 4, no. 1, pp. 88-95, 2014.

[12] P. Hamer, B. Hallam, S. Wenham, and M. Abbott, "Manipulation of hydrogen charge states for passivation of P-type wafers in photovoltaics," IEEE Journal of Photovoltaics, vol. 4, no. 5, pp. 1252-1260, 2014.

[13] R. Rizk, P. de Mierry, D. Ballutaud, M. Aucouturier, and D. Mathiot, "Hydrogen diffusion and passivation processes in $p$ and $n$-type crystalline silicon," Physical Review B, vol. 44, no. 12, pp. 6141-6151, 1991.

[14] C. Herring, N. M. Johnson, and C. G. van de Walle, "Energy levels of isolated interstitial hydrogen in silicon," Physical Review B: Condensed Matter and Materials Physics, vol. 64, no. 12, Article ID 125209, 2001.

[15] S. Estreicher, "Equilibrium sites and electronic structure of interstitial hydrogen in Si," Physical Review B, vol. 36, no. 17, pp. 9122-9128, 1987.

[16] B. Tuttle, C. G. van de Walle, and J. B. Adams, "Exchange of deeply trapped and interstitial hydrogen in silicon," Physical Review B-Condensed Matter and Materials Physics, vol. 59, no. 8, pp. 5493-5497, 1999.

[17] J. I. Pankove, D. E. Carlson, J. E. Berkeyheiser, and R. O. Wance, "Neutralization of shallow acceptor levels in silicon by atomic hydrogen," Physical Review Letters, vol. 51, no. 24, pp. 22242225, 1983.

[18] N. M. Johnson, C. Herring, and D. J. Chadi, "Interstitial hydrogen and neutralization of shallow-donor impurities in single-crystal silicon," Physical Review Letters, vol. 56, no. 7, pp. 769-772, 1986.

[19] A. Liu, C. Sun, and D. Macdonald, "Hydrogen passivation of interstitial iron in boron-doped multicrystalline silicon during annealing," Journal of Applied Physics, vol. 116, no. 19, Article ID 194902, 2014.

[20] S. Wilking, C. Beckh, S. Ebert, A. Herguth, and G. Hahn, "Influence of bound hydrogen states on BO-regeneration kinetics and consequences for high-speed regeneration processes," Solar Energy Materials and Solar Cells, vol. 131, pp. 2-8, 2014.

[21] B. Lim, S. Hermann, K. Bothe, J. Schmidt, and R. Brendel, "Permanent deactivation of the boron-oxygen recombination center in silicon solar cell," in Proceedings of the 23rd European Photovoltaic Solar Energy Conference and Exhibition, pp. 10181022, Valencia, Spain, 2008.

[22] G. Krugel, W. Wolke, J. Geilker, S. Rein, and R. Preu, "Impact of hydrogen concentration on the regeneration of light induced degradation," Energy Procedia, vol. 8, pp. 47-51, 2011.
[23] P. V. Santos, N. M. Johnson, and R. A. Street, "Light-enhanced hydrogen motion in a-Si:H," Physical Review Letters, vol. 67, no. 19, pp. 2686-2689, 1991.

[24] D. Kray, S. Hopman, A. Spiegel, B. Richerzhagen, and G. P. Willeke, "Study on the edge isolation of industrial silicon solar cells with waterjet-guided laser," Solar Energy Materials and Solar Cells, vol. 91, no. 17, pp. 1638-1644, 2007.

[25] S. Wenham, "Buried-contact silicon solar cells," Progress in Photovoltaics: Research and Applications, vol. 1, no. 1, pp. 3-10, 1993.

[26] U. Besu-Vetrella, "Large area, screen printed silicon solar cells with selective emitter made by laser overdoping and RTA spin-on glasses," in Proceedings of the 26th IEEE Photovoltaic Specialists Conference: Conference Record, September 1997.

[27] M. Abbott and J. Cotter, "Optical and electrical properties of laser texturing for high-efficiency solar cells," Progress in Photovoltaics: Research and Applications, vol. 14, no. 3, pp. 225235, 2006.

[28] A. Knorz, M. Peters, A. Grohe, C. Harmel, and R. Preu, "Selective laser ablation of $\mathrm{SiN}_{x}$ layers on textured surfaces for low temperature front side metallizations," Progress in Photovoltaics: Research and Applications, vol. 17, no. 2, pp. 127-136, 2009.

[29] Y. Park, J. Lu, and G. Rozgonyi, "Segregation and thermal dissociation of hydrogen at the $(110) /(001)$ silicon grain boundary," Electronic Materials Letters, vol. 6, no. 1, pp. 1-5, 2010.

[30] K. Nakayashiki, A. Rohatgi, S. Ostapenko, and I. Tarasov, "Minority-carrier lifetime enhancement in edge-defined filmfed grown Si through rapid thermal processing-assisted reduction of hydrogen-defect dissociation," Journal of Applied Physics, vol. 97, no. 2, Article ID 024504, 2005.

[31] H. Y. Cho, E. K. Kim, S.-K. Min, K. J. Chang, and C. Lee, "Electric-field-enhanced dissociation of the hydrogen-Si donor complex in GaAs," Journal of Applied Physics, vol. 68, no. 10, pp. 5077-5080, 1990.

[32] C. G. van de Walle, "Energies of various configurations of hydrogen in silicon," Physical Review B, vol. 49, no. 7, article 4579, 1994.

[33] T. Zundel and J. Weber, "Trap-limited hydrogen diffusion in boron-doped silicon," Physical Review B, vol. 46, no. 4, pp. 20712077, 1992.

[34] S. T. Pantelides, "Effect of hydrogen on shallow dopants in crystalline silicon," Applied Physics Letters, vol. 50, no. 15, pp. 995-997, 1987.

[35] D. Mathiot, "Modeling of hydrogen diffusion in $n$ - and $p$-type silicon," Physical Review B, vol. 40, no. 8, pp. 5867-5870, 1989.

[36] E. R. Weber, "Transition metals in silicon," Applied Physics A: Solids and Surfaces, vol. 30, no. 1, pp. 1-22, 1983.

[37] L. A. Hemstreet, "Electronic states of simple-transition-metal impurities in silicon," Physical Review B, vol. 15, no. 2, pp. 834839, 1977.

[38] T. Sadoh, M. Watanabe, H. Nakashima, and T. Tsurushima, "Deep levels of chromium-hydrogen complexes in silicon," Journal of Applied Physics, vol. 75, no. 8, pp. 3978-3981, 1994.

[39] T. Sadoh, H. Nakashima, and T. Tsurushima, "Deep levels of vanadium and vanadium-hydrogen complex in silicon," Journal of Applied Physics, vol. 72, no. 2, pp. 520-524, 1992.

[40] W. Jost and J. Weber, "Titanium-hydrogen defects in silicon," Physical Review B, vol. 54, no. 16, pp. R11038-R11041, 1996.

[41] A. Zunger and U. Lindefelt, "Electronic structure of transitionatom impurities in semiconductors: substitutional $3 \mathrm{~d}$ impurities in silicon," Physical Review B, vol. 27, no. 2, pp. 1191-1227, 1983. 
[42] J. R. Davis Jr., A. Rohatgi, R. H. Hopkins et al., "Impurities in silicon solar cells," IEEE Transactions on Electron Devices, vol. 27, no. 4, pp. 677-687, 1980.

[43] R. Singh, S. J. Fonash, and A. Rohatgi, "Interaction of lowenergy implanted atomic $\mathrm{H}$ with slow and fast diffusing metallic impurities in Si," Applied Physics Letters, vol. 49, no. 13, pp. 800802, 1986.

[44] T. Sadoh, H. Nakashima, and T. Tsurushima, "Deep levels of vanadium and vanadium-hydrogen complex in silicon," Journal of Applied Physics, vol. 72, no. 2, pp. 520-524, 1992.

[45] P. Broqvist, A. Alkauskas, and A. Pasquarello, "Defect levels of dangling bonds in silicon and germanium through hybrid functionals," Physical Review B: Condensed Matter and Materials Physics, vol. 78, no. 7, Article ID 075203, 2008.

[46] S. Olibet, E. Vallat-Sauvain, and C. Ballif, "Model for a-Si:H/c$S i$ interface recombination based on the amphoteric nature of silicon dangling bonds," Physical Review B, vol. 76, no. 3, Article ID 035326, 2007.

[47] B. Sopori, Y. Zhang, and N. M. Ravindra, "Silicon device processing in $\mathrm{H}$-ambients: $\mathrm{H}$-diffusion mechanisms and influence on electronic properties," Journal of Electronic Materials, vol. 30, no. 12, pp. 1616-1627, 2001.

[48] B. L. Sopori, X. Deng, J. P. Benner et al., "Hydrogen in silicon: a discussion of diffusion and passivation mechanisms," Solar Energy Materials and Solar Cells, vol. 41-42, pp. 159-169, 1996.

[49] F. Jiang, M. Stavola, A. Rohatgi et al., "Hydrogenation of Si from $\operatorname{SiN}_{x}(H)$ films: characterization of $\mathrm{H}$ introduced into the $\mathrm{Si}$," Applied Physics Letters, vol. 83, no. 5, pp. 931-933, 2003.

[50] R. Biswas, Q. Li, B. C. Pan, and Y. Yoon, "Mechanism for hydrogen diffusion in amorphous silicon," Physical Review B, vol. 57, no. 4, pp. 2253-2256, 1998.

[51] S. R. Wenham, P. G. Hamer, B. J. Hallam et al., "Advanced hydrogenation of silicon solar cells," Google Patents, 2013.

[52] J.-W. Jeong, A. Rohatgi, V. Yelundur, A. Ebong, M. D. Rosenblum, and J. P. Kalejs, "Enhanced silicon solar cell performance by rapid thermal firing of screen-printed metals," IEEE Transactions on Electron Devices, vol. 48, no. 12, pp. 2836-2841, 2001.

[53] V. Meemongkolkiat, M. Hilali, and A. Rohatgi, "Investigation of RTP and belt fired screen printed AL-BSF on textured and planar back surfaces of silicon solar cells," in Proceddings of the 3rd World Conference on Photovoltaic Energy Conversion, pp. 1467-1470, May 2003.

[54] T. Trupke, R. A. Bardos, M. C. Schubert, and W. Warta, "Photoluminescence imaging of silicon wafers," Applied Physics Letters, vol. 89, no. 4, Article ID 044107, 2006.

[55] J. A. Giesecke, M. C. Schubert, B. Michl, F. Schindler, and W. Warta, "Minority carrier lifetime imaging of silicon wafers calibrated by quasi-steady-state photoluminescence," Solar Energy Materials and Solar Cells, vol. 95, no. 3, pp. 1011-1018, 2011.

[56] M. S. Ahmmed, T. Talei, E. R. Hawkes, L. Song, and S. Wenham, "Thermal simulation of laser annealing for hydrogenation of cSi in solar cells," in Proceedings of the 52nd Annual Conference of the Australian Solar Energy Society, Melbourne, Australia, May 2014.

[57] A. Rohatgi and J.-W. Jeong, "High-efficiency screen-printed silicon ribbon solar cells by effective defect passivation and rapid thermal processing," Applied Physics Letters, vol. 82, no. 2, pp. 224-226, 2003.

[58] J. C. Muller, V. T. Quat, P. Siffert, H. Amzil, A. Barhdadi, and N. M'Gafad, "Temperature parameter in hydrogen passivation of multicrystalline silicon solar cells," Solar Cells, vol. 25, no. 2, pp. 109-125, 1988.
[59] A. Sugianto, J. Bovatsek, S. Wenham et al., "18.5\% laser-doped solar cell on CZ p-type silicon," in Proceedings of the 35th IEEE Photovoltaic Specialists Conference (PVSC '10), June 2010.

[60] B. C. Stuart, M. D. Feit, A. M. Rubenchik, B. W. Shore, and M. D. Perry, "Laser-induced damage in dielectrics with nanosecond to subpicosecond pulses," Physical Review Letters, vol. 74, no. 12, pp. 2248-2251, 1995.

[61] V. Yelundur, A. Rohatgi, A. Ebong, A. M. Gabor, J. Hanoka, and R. L. Wallace, "Al-enhanced PECVD $\mathrm{SiN}_{x}$ induced hydrogen passivation in string ribbon silicon," Journal of Electronic Materials, vol. 30, no. 5, pp. 526-531, 2001.

[62] J. K. R. Einhaus, F. C. Y. Caratini, D. Bernou et al., "Photosilsimplified production of solar silicon from metallurgical silicon," in Proceedings of the 21st European Photovoltaic Solar Energy Conference (PVSEC '06), pp. 580-584, Dresden, Germany, 2006.

[63] M. B. Rabha, W. Dimassi, M. Bouaïcha, H. Ezzaouia, and B. Bessais, "Laser-beam-induced current mapping evaluation of porous silicon-based passivation in polycrystalline silicon solar cells," Solar Energy, vol. 83, no. 5, pp. 721-725, 2009.

[64] P. A. Basore, "Extended spectral analysis of internal quantum efficiency," in Proceedings of the 23rd IEEE Photovoltaic Specialists Conference, pp. 147-152, May 1993. 

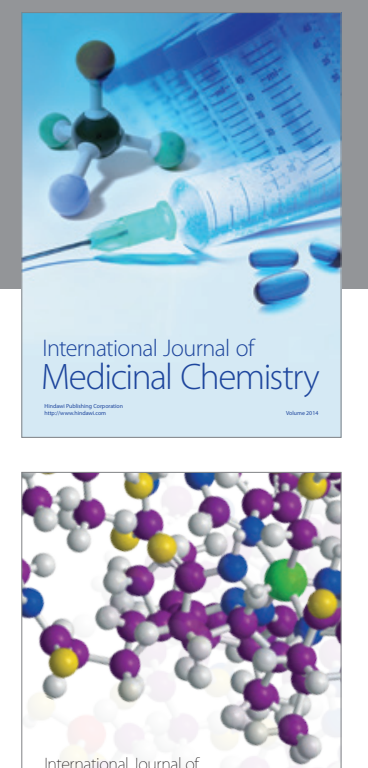

\section{Carbohydrate} Chemistry

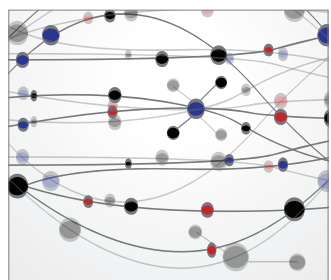

The Scientific World Journal
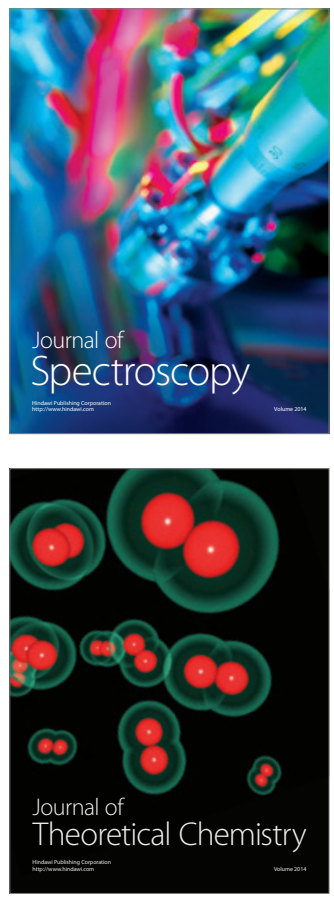
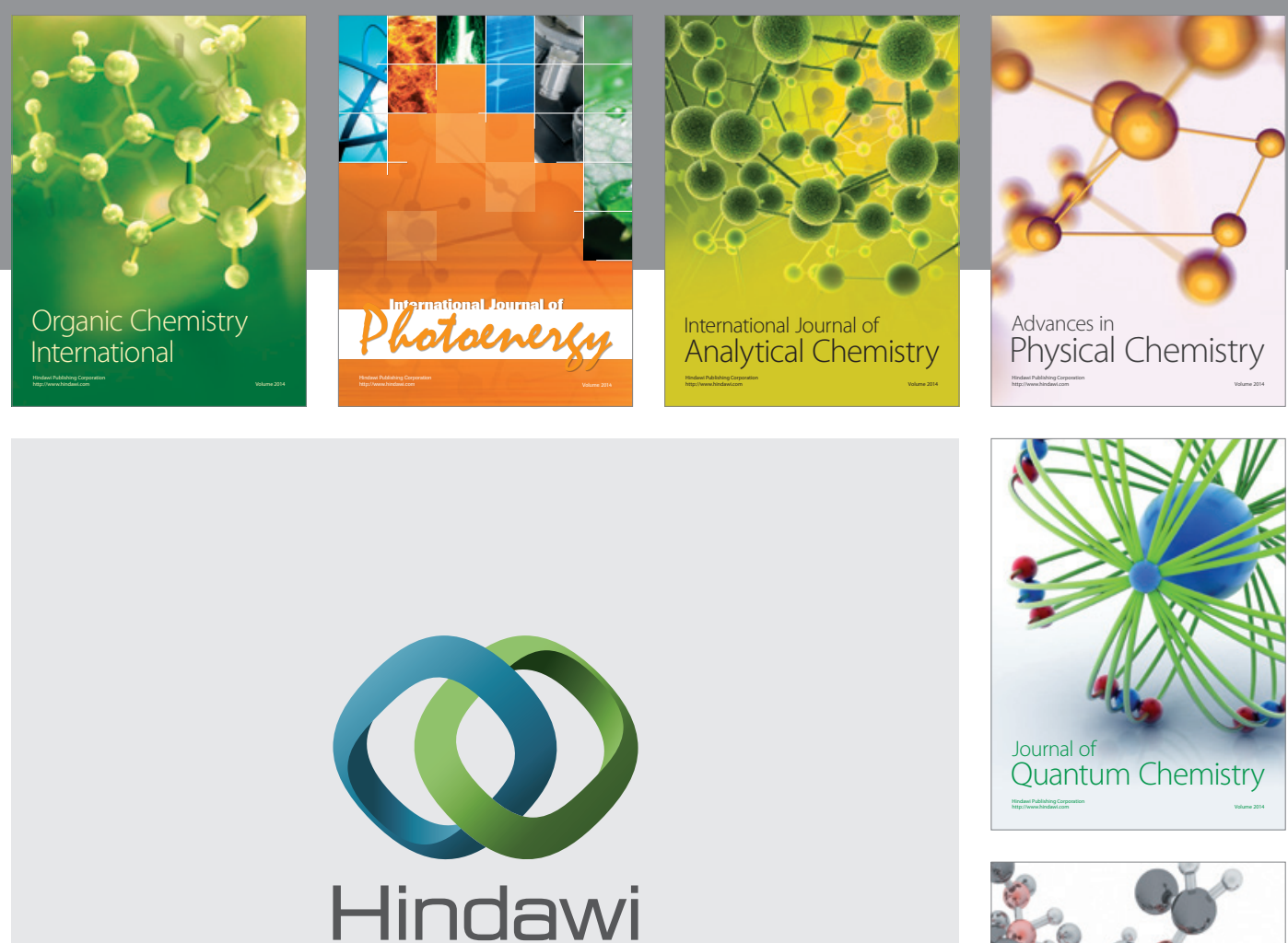

Submit your manuscripts at

http://www.hindawi.com

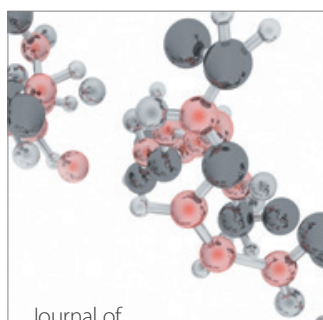

Analytical Methods

in Chemistry

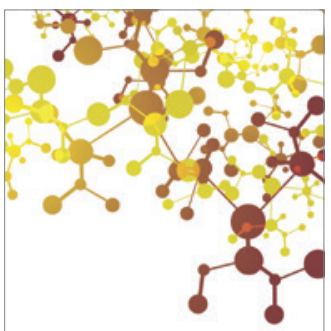

Journal of

Applied Chemistry

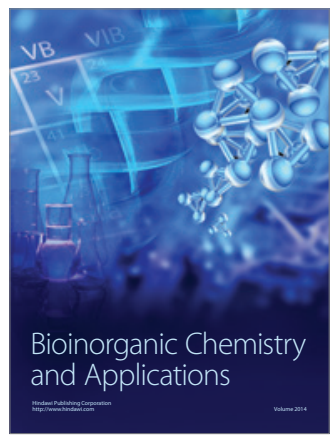

Inorganic Chemistry
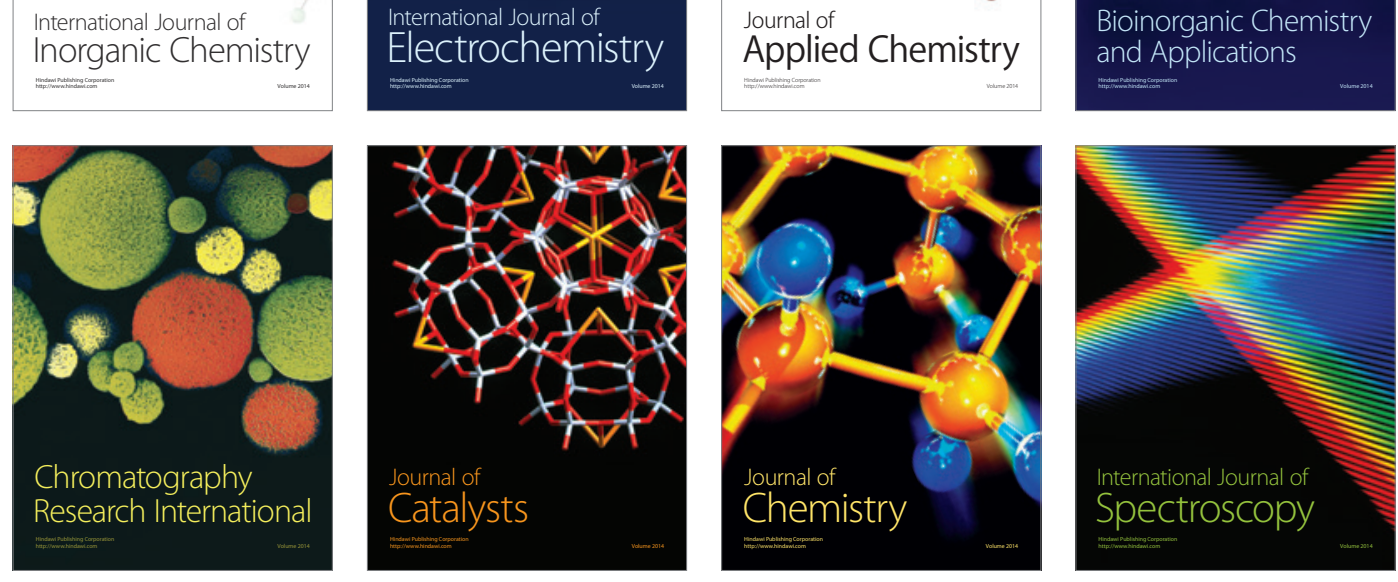